\title{
PRESUPUESTOS METODOLÓGICOS PARA EL ESTUDIO INSTITUCIONAL DE LAS CORTES MEDIEVALES ARAGONESAS
}

\author{
Jesús Lalinde Abadía
}

Justificación de la intervención en el tema de las cortes aragonesas.

Los fucros, las cortes o el justicia son temas a cuyo tratamiento está econdenados el iushistoriador que dedique su atención al reino de Aragón. Son dificiles por su amplitud y complejidad, lo que ha ocasionado el que yo no los haya buscado expresamente, aunque tampoco haya tratado de rehuirlos. Hasta el momento no he tenido que abordar el tercero ${ }^{1}$, pero sí $\mathrm{cl}^{\text {primero }}{ }^{2}$, y ahora me veo abocado al segundo. Tengo interés en insistir que la iniciativa no es mía, pues no tengo deseos de polemizar y, sin embargo, ello es inevitable, en cuanto mi postura en el tema ha sido criticada, y observar silencio sería peor porque podría interpretarse como desprecio hacia las posturas adversas. Desde luego, procuraré hacerlo sin acritud, y con el deseo de no molestar a nadie, pues también entiendo que no ha existido la intención de molestarme a mí.

1 Me he limitado a su exposición como voz en.la Gran Enciclopedia Aragone$s a$, actualmente en curso de publicación, aunque me he ocupado de su evolución en la época de los Austrias en un trabajo próximo a publicar en el Anuario de Historia del Derecho Español.

2 Los Fueros de Aragón, Colección Aragón, Librería General, Zaragoza, 1976. 
El tema señalado por la organización de las jornadas es el de las cortes medievales aragonesas, pero hacer una exposición general, sea histórica, sea institucional, no creo que ofrezca interés, pues tendría que consisitir en una repetición del contenido de los libros existentes ahora en el mercado. Sin embargo, como estos libros, en el aspecto institucional, difieren de las obras anteriores, y aún difieren entre sí, me ha parecido más útil tomarme la libertad de aprovechar la tribuna ofrecida para exponer algunas reflexiones sobre los presupuestos metodológicos de los que, a mi juicio, debería partirse para realizar el estudio institucional serio que demanda el estado actual de la investigación. Creo que en el aspecto histórico puro se está progresando de forma mantenida, pues poseemos nuevas aportaciones documentales y se aprovecha al máximo la información de que disponemos.

Creo que esto no tiene su debida correlación en el aspecto institucional, en el que, últimamente, aunque no siempre, se ha sembrado la confusión, y ésta es una siembra que suele dar abundantes cosechas, porque la confusión no desagrada, fenómeno que me desconcierta, y que sospecho pueda deberse al principio contenido en el adagio *a tío revuelto, ganancia de pescadores», en el sentido de que la confusión permite la intervención general y la adopción de mayores licencias a la hora de intervenir o de opinar.

La existencia de historiografias clásica, romántica y contemporánea sobre las cortes aragonesas.

En el momento actual existen tres historiografias a las que convencionalmente podemos denominar «clásica», «romántica» y «realistas o *contemporáneas. La primera es la que corresponde a los siglos XVI y XVII, y, por tanto, quizá sería más correcto denominarla «renacentista» y abarroca», pero en cuanto es la más antigua y a la que se recurre en primer lugar, y como punto de partida, podemos llamarla «clásica». La segunda transcurre a lo largo del siglo XIX y las tres primeras décadas del XX, y, a diferencia de la primera, no aborda el tema monográficamente, sino que lo trata dentro del tema general de la *constitución» aragonesa. La historiografia contemporánea vuelve a tratar el tema monográficamente, como lo hacia la clásica, y puede denominársele «realista», más que por serlo en sí, que lo es en el sentido de querer percibir lo que auténticamente pasó, porque cree que las anteriores historiografias no lo fueron, especialmente la romántica. 
La historiografía clásica, aparte de Jerónimo Zurita, que no trata el tema monográficamente, está constituida pot los cronistas del reino, Jerónimo de Blancas, Jerónimo Martel y Juan Francisco Andrés de Ustarroz. Blancas, perteneciente a un antiguo linaje, es un notable humanista como discípulo del Maestro Nuñez, aunque, a diferencia de algunos humanistas italianos, por ejemplo, es profundamente religioso, sucediendo a Jerónimo Zurita como cronista del reino en $1581^{3}$. En tanto Zurita es el modelo del historiador positivista «a lo Ranke», que parece buscar el conocimiento por el conocimiento en sí, Blancas lo es del ideólogo, para el que la Historia es un instrumento al servicio de un objetivo político, en este caso la causa aragonesa, hasta el punto de que alguna de sus obras, como es la de los Comentarios sobre los asuntos de Aragón, se publica con dificultad ante las suspicacias del Consejo de Aragón y del mismo Felipe II, y en ella culmina la vieja leyenda de los Fueros de Sobrarbe en seis lapidarias leyes redactadas en latín arcaico $^{4}$. La obra de Blancas es de las ede encargo», en lo que no se diferencia de la de Zurita, y, concretamente, por lo que se refiere a las cortes, es escrita por estímulo de los diputados del reino, que, ante una inminente visita del rey, le aconsejan reconocer los Registros de las Cortes, lo que sabemos por el prólogo del propio Blancas. Empieza con los existentes en el Archivo de la Diputación, a los que dice ya había «dado bueltas, pero para escribir la historia que le corresponde en su oficio de cronista. Blancas reconoce que no pudo cumplir su tarea, porque los registros eran muchos y voluminosos, y que, además, no vio los registros que estaban en poder del protonotario y del notario de las Cortes. Sin embargo, y esto retrata también a Blancas, ello no le arredra, como es posible que le hubiera arredrado a Zurita, y estima que sería peor no publicar las noticias, aunque éstas sean incompletas, que ofrecer una obra, que hoy diríamos redactada por el sistema de «mues-

3 Vid. M. GOMEZ URIEL, Bibliotecas antigua y nueva de escritores aragoneses de Latassa, aumentadas y refundidas en forma de Diccionario bibliográficobiográfico. Imprenta de Calixto Ariño, tomo 1, Zaragoza, 1884, donde se da noticia de su muerte por apoplejía.

4 Lo he destacado en op. cif., en nota 2, p. 114 y ss. La obra de Blancas aparece como «Modo de proceder en cortes de Aragón. Escrito por Geronimo de Blancas chronista del Reyno. A los quatro brazos del reyno iuntos en cortes generales... Publicado el Doctor Iuan Francisco Anàres de Ustarroz, con algunas Notas. Con Licencia y Privilegio, en Zaragoça, por Diego Dormer. Año M. DC. XII. A costa del Reyno*. 
treos, el cual, por otra parte, y cuando se examina el trabajo, aparece reducido a las cortes de su época, es decir, a las del siglo XVI, y a las de épocas inmediatamente anteriores, como el s. XV, muy rico, por otra parte, al que hay que asociar los nombres de Maella, Teruel, Alcañiz, Zaragoza y, sobre todo, Calatayud. Aunque las cite, no parece que haya examinado los registros de cortes de siglos anteriores. Blancas, representante de una dirección conceptual o dogmática, frente a la histórica positivista de Zurita, desea ereduzir a algun método» una materia que estima «tan mal entendida» hasta ese momento y de cuya tarea han desistido muchos por ser materia incierta, ya que el hacer y deshacer del rey y del reino y modificar hasta el modo de proceder, en los registros es posible hallar en ellos «no uno, sino mil exemplares*. Blancas, pues, como gran conceptualizador, no se engaña sobre el carácter cambiante de la institución, pero ello no le impide reducir «a lugares comunes» lo examinado, cosa que hace en ventiún capítulos, a lo largo de los cuáles se ofrece una visión precisa del concepto, clases, sujetos, lugar, tiempo, procedimiento y, en general, toda la problemática que ofrece una asamblea de naturaleza representativa.

Martel, zaragozano perteneciente a un antiguo linaje procedente de Burdeos, tiene en común con Blancas el ser un notable humanista; el desempeñar el oficio de cronista del reino, en el que sucede al Dr. Juan Costa en 30 de junio de 1597 por fallecimiento de aquél; el haber encontrado obstáculos para la publicación de sus trabajos, en especial la continuación de los Anales de Zurita, y el poseer una mente sistematizadora'. Se aparta, sin embargo, ideológicamente de Blancas, seguramente por los años que le corresponde vivir. En tanto Blancas vive los de apogeo del aragonesismo antifilipista y muere poco antes de que se consume la reacción regía, Martel se ve directamente afectado por ésta. D. Juan Francisco de Ariño, señor de las baronías de Ossera y Figueruela, le encarga un sumario de la obra de Blancas, lo que da lugar a que elabore su obra sobre las cortes, que envía a D. Jorge Fernández de Heredia, gentil hombre de la boca del rey, quien la publica en

s La obra de Martel se publica como «Forma de celebrar cortes en Aragón. Escrita por Geronimo Martel chronista del Reyno. Publicala el Dactor Iuan Francisco Andres de Ustarroz, con algunas Notas. En Zaragoça, por Diego Dormer. Año M. DC. XLIs. Ustarroz historia a Martel. Su escudo está constituido por tres martillos. Debió casarse tardíamente con Da Elena de Hueste, y descendía de Pedro Martel, quien impulsó a Jaime I a conquistar Mallorca. 
las cortes de Tarazona de 1592, y los diputados del reinado, pasadas aquéllas, le encargan un índice substanciado de las obras de Zurita, la ordenación del Archivo y la corrección de su obra con arreglo a lo legislado en las indicadas cortes. Como es frecuente entre nosotros, Martel se muestra mezquino con Blancas en cuanto coetáneo, mezquindad que aún resalta más si se tiene en cuenta que cuando él escribe ya ha muerto.su «rivalo literario. En efecto, Martel destaca que añadió muchas cosas particulares que no había tratado Blancas, y subraya que no se explica por qué no lo hizo éste siendo cosas tan importantes. La verdad es, sin embargo, que aunque alguna vez corrige a Blancas, no añade nada substancial a la obra de éste, salvo, naturalmente, la legislación de las cortes de Tarazona de 1592 , que Blancas no alcanzó. El prólogo de su obra aparece ya fechado en 15 de enero de 1601 .

La función de Juan Francisco Andrés de Ustarroz es la de anotador y editor de Blancas y de Martel. Nacido en Zaragoza en 1606, es cronista del reino en 9 de enero de 1657 al fallecimiento de Francisco Giménez de Urrea, y muere en Madrid el 18 de agosto de $1677^{6}$. En algunos capítulos las notas de Andrés de Ustarroz son más extensas que el texto de Blancas, aunque también hay capítulos que no anota. Como tales notas son de carácter erudito, es decir, precisiones a citas. En cierta manera, puede decirse que es un historiógrafo, pues se ocupa de biografiar y dar a conocer a sus antecesores en el cargo de cronista del reino. Por otra parte, y conforme a la concepción de la época, en sus biografias presta más atención al linaje que al individuo, respondiendo más al tipo del genealogista que al tipo del biógrafo, tal como lo concebimos en nuestro tiempo. Al igual que Blancas, Andrés de Ustarroz tiene siempre en cuenta a la Corona de Áragón, y, en especial, a Cataluña, siendo destacable que Blancas conoce muy bien la obra de Jaime Callís, como Andrés de Ustarroz la obra de Andrés Bosch ${ }^{7}$.

No sé si puede decirse que la historiografía romántica se inicia con Antonio de Capmany, o que, al menos, éste es un prerromántico, como lo es Martínez Marina en Castilla. El doceañista catalán elabora una obra sobre las cortes en la Corona de Aragón, utilizando las historiografías clásicas, y para Aragón, concretamente,

6 Vid. los datos en GOMrz URIEL, op. cit., tomo I, p. 58.

7 Sobre Callís vid. mi libro eLa persona y la obra del jurisconsulto vicense Jaume Calliss. Vic, 1980 . He utilizado mucho a Andrés Bosch en mi libro La instituciōn virreinal en Cataluña, Barcelona, 1964. 
la obra de Andrés de Ustarroz ${ }^{8}$. Es un prerromántico en el sentido de que inicia una labor de exaltación de las cortes medievales, con el propósito de que sirvan de modelo, en parte, para las cortes constitucionales, y será interesante investigar si el catalán intentaba sugerir modelo distinto al que sugería el asturiano. Después, y como ya se ha dicho, viene la pléyade de historiadores del siglo $\mathrm{XIX}$, que, sin ocuparse monográficamente de las cortes, las tienen en cuenta como pieza importante de una constitución medieval aragonesa, que algunos oponen al centralismo del primer liberalismo constitucional ${ }^{9}$, y cuya última figura es, probablemente, la de López de Haro en $1926^{10}$.

La historiografia realista, desde el punto de vista monográfico, se inicia en 1953 con un breve artículo de Luis Felipe Arregui Lucea $^{11}$, que utiliza la historiografía clásica en las figuras de Blancas y de Martel, así como también la romántica en la de López de Haro, pero también la posterior de del Arco y de Giménez Soler, figura ésta que hubiera podido jugar un papel importante si se hubiera dedicado más específicamente al tema. La aportación actual procede del círculo de discípulos directos o indirectos del Prof. José Ma Lacarra, en el Departamento de Historia Medieval, de la Facultad de Filosofía y Letras de Zaragoza. Parte de las aportaciones han sido de orden documental, como extractos y fragmentos de procesos de cortes correspondientes al período 1357 . 1451 , alguno de ellos procedente de Blancas, que han sido publicados por los doctores A. Sesma Muñoz y E. Sarasa ${ }^{12}$, o las actas de un proceso de cortes celebradas en Tamarite, en 1375, y que se debe a la profesora adjunta M. ${ }^{a}$ Luisa Ledesma Rubio, las cuales nos permiten conocer las arduas negociaciones que preceden a la concesión de un adono o atorgamiento ${ }^{13}$.

8 A. DE CAPMany MONTPALAU, Práctica y estilo de celebrar Cortes en el reino de Aragón, principado de Cataluña y reino de Valencia, Madrid, 1821.

${ }^{9}$ En op. cit. en nota 2, p. 150 y ss. me he ocupado de Quinto, Morales, Lasala, etc.

10 C. LOPfZ Haro, La Constitución y libertades de Aragón y el Justicia Mayor, Madrid, 1926.

11 L.F. ARreguI LUCEAL. sLa curia y las cortes en Aragón. Argensolas, Revista del Instituto de Estudios Oscenses, núm. 13. Huesca, 1953, pp. 1-36.

12 A. Sesma Munoz y E. Sarasa Sínchez, *Cortes del Reino de Aragón. 1357-1451. Extractos y fragmentos de procesos desaparecidos», Textos Medievales, 47. Valencia, 1976.

${ }^{13}$ Ma L. Ledesma Rubio, *Actas de proceso de Cortes de Tamarite de 1375. 
La aportación doctrinal se contiene, fundamentalmente, en dos libros a los que separa un año aproximadamente en su publicación, pero que en ambos casos son remate de una actividad anterior, debiendo observarse que no será dato indiferente para los que acometan la semblanza del Aragón de nuestros días el que, tras tantos años estériles, casi en el mismo año aparezcan dos libros sobre el tema. El primero en orden de aparición es el del Dr. Luis González Antón, que no tiene límites temporales y que se inserta en una colección de temas aragoneses ${ }^{14}$. El autor se había ocupado anteriormente de reuniones de cortes determinadas, como las del período de Pedro III y de Jaime II ${ }^{15}$. En la citada obra dedida un «preliminar» a los «parlamentos» en la Baja Edad Media $y$ aprimera edad modernas, $y$ tres partes al nacimiento de las cortes en la época de la adinastía Barcelonas; las cortes de Aragón con los xúltimos Barcelona» y los Trastámara, y la decadencia de las cortes en la edad moderna ${ }^{16}$, ofreciendo amplia bibliografía.

El otro libro corresponde al Dr. Esteban Sarasa Sánchez, uno de los que, como se recordará, han ofrecido algunos extractos y fragmentos de procesos de corte desaparecidos. Como el anterior, el libro se inserta en una colección de temas aragoneses ${ }^{17}$, pero, a diferencia de aquél, se limita al período medieval, estudiándose, tras unas consideraciones sobre la historiografia, los orígenes y evolución de la institución, el procedimiento, las competencias, el ceremonial y protocolo, y las fuentes, ofreciéndose una bibliografía breve pero seleccionada.

Ambas obras, la de L. González Antón y la de E. Sarasa, son de diferente talante. La del primero, con mucha información, apoyada en propios trabajos anteriores, estilo profuso y abundante en neologismos, está animada de un espíritu que hoy se denomina «desmitificador», y que en tiempos no muy lejanos se calificaba de

Textos Medicvales. 57. Anubar Ediciones.. Zaragoza, 1979, y Cortes de Caspe. Alcañiz y Zaragoza de 1371-72. Anúbar, Valencia, 1975.

14 L. Gonzalfz, ANTON, Las Cortes de Aragón. Zaragoza, 1978. La colección es «Colección Aragón», de Libreria General, que se inauguró con el libro cit. en nota 2.

is L. Gonz.Áliz. Ant'ón, Las Uniones aragonesas y las Cortes del Reino (12831301), CSIC, 2 vols. Zaragoza, 1975 y Las Cortes aragonesas en el reinado de Jaime II, AHDE, XLVII, 1977, pp. 523-682.

16 Los entrecomillados responden a neologismos y anacronismos respecto a nuestra época, o a expresiones incorrectas, al menos, descuidadas.

17 E. Sarasa Sanchiz. Las Cortes de Aragón en la Edad Media, Zaragoza, 1979. La colección es la «Básica aragonesa», de Guara Editorial. 
«iconoclastas. Aspira constantemente a derribar lugares comunes y su método es, preferentemente, analítico, lo que queda confirmado cuando la necesidad de síntesis le lleva a periodificaciones cronológicas, sin calificación conceptual. La obra del segundo, con estilo conciso y cuidado, así como con ausencia de neologismos, es de corte clásico y conciliador entre los lugares comunes consagrados en la historiografia tradicional, y las nuevas corrientes desmitificadoras, concediendo concesiones a estas últimas en la primera parte del libro, a través, especialmente, de elogios a la obra de L. González Antón y crítica a la influencia de los historiadores del Derecho, que luego no aparecen muy confirmadas en el desarrollo de los distintos aspectos institucionales, donde su postura es siempre de moderación.

\section{La necesidad de acercamiento entre las posturas analítica y sintética ante la siembra de un confusionismo axiológico.}

En todo caso, independientemente de que se esté de acuerdo o no, las obras de L. González Antón y de E. Sarasa han enriquecido el panorama historiográfico aragonés en el tema de las cortes, como la de otros autores recientes lo han hecho en el terreno de las fuentes, o en el de instituciones como la Diputación y los municipios ${ }^{18}$. Sin embargo, este enriquecimiento, que es claro en el aspecto histórico general, no lo es a causa del confusionismo axiológico que ha sembrado la obra del primero y que, desgraciadamente, no ha compensado suficientemente la del segundo. Con la expresión «siembra de confusionismo axiológico» me refiero a la de las dudas en la valoración o estimación de las cortes en sus diferentes aspectos. En los manuales de historia general, historia del Derecho o historia de las instituciones, se estudiaba que las cortes aragonesas eran de naturaleza periódica, tenían competencia legislativa, representaban al reino y resultaban de la evolución de la curia regia altomedieval, por ejemplo, entre otras notas. Sin embargo, en la actualidad el lector de esos manuales puede encontrarse con obras que dicen que las cortes no nacen propiamente hasta 1283, que no legislan, que no se reúnen periódicamente y que no representan a nadie, o, en todo caso, a unos cuantos no-

18 Pueden citarse los nombres de A. San Vicente Pino, Angel Sesma Muñoz e Isabel Falcón, entre otros. 
bles. El lector se verá sumido en un mar de dudas porque ahora no se rectifican los juicios anteriores, sino se contradicen frontalmente, y no algunos de ellos, sino todos. Ésta es una situación altamente perjudicial para la historia de las instituciones, y tenemos que superarla entre todos, lo que precisa de un acercamiento entre las posturas analíticas y sintéticas. Propendiendo las primeras a encontrar diferencias en los casos que analizan, desembocan en un nominalismo que excluye toda existencia de rasgos comunes en la institución a través de sus estadios. Las segundas, sin embargo, no desconocen la existencia de rasgos diferenciales, pero pretenden elaborar categorías a través de los rasgos comunes, pues sólo la conceptualización lleva al hombre a un conocimiento superior de las cosas y de los hechos. La cuestión no está en que los analíticos dejen de realizar sus análisis, sino, al contrario, que los profundicen, pero para que sus resultados no sean meramente negadores, sino para que el conocimiento de las categorías pueda aparecer más perfilado, estableciendo, incluso, todas aquellas subcategorías o divisiones categoriales que se precisen.

$\mathrm{El}$ indicado acercamiento sólo puede realizarse a través de la aceptación común de unos presupuestos metodológicos para el estudio instirucional, es decir, adoptando previamente un lenguaje común. Ese esfuerzo es el que pretendo iniciar en el resto de esta exposición, referido concretamente al tema de las cortes medievales aragonesas.

\section{La obligación de una utilización crítica de la bibliografia.}

Herederos de la edad media, seguimos afectos al criterio de autoridades. Nos quedamos totalmente tranquilos si una aseveración nuestra la podemos apostillar con la cita de un autor célebre o menos célebre, sin preocuparnos si la cita es completa o incompleta; si es concordante con el resto de la obra; si el supuesto al que el autor la ha aplicado es similar al que la aplicamos ahora; o si el citado es una verdadera autoridad en el hecho concreto en el que se le cita. No creo posible apoyar una aseveración en dos autores tan dispares cronológica y conceptualmente como Carlyle y Ourliac ${ }^{19}$;

19 González Antón, op, cit. en nota 14, p. 26. Entre Carlyle y Ourliac no existe comunidad de nación, lengua, época, ideología o corriente metodológica. Es un contubernio científico. 
utilizar a W. Ullmann contra «muchos* historiadores del Derecho sin que uno y otros hayan contemplado la misma materia o un supuesto común ${ }^{20}$; ampliar a otros territorios lo que Pérez-Prendes ha dicho para uno de ellos ${ }^{21}$; apoyar una comparación entre territorios distintos con autores, que sólo se han referido a uno de los dos términos de la comparación, y no, a todos ellos ${ }^{22}$, y medios similares.

Cada vez más, creo que en el futuro es necesario substituir el sistema abstracto de citas por la orientación historiográfica, donde lo que se valore sea la posición total de un autor, o, al menos, la de una de sus obras, eliminando el vicioso sistema de entresacar líneas de él, que extraídas de su contexto pueden ser poco o nada representativas.

\section{La conveniencia de respetar las denominaciones históricas.}

Es cierto que nosotros no podemos reproducir el lenguaje coetáneo en el tratamiento de las instituciones, pero debemos respetar las denominaciones substanciales, a menos que expliquemos por qué no lo hacemos en el caso concreto, y el código que entonces vamos a urilizar. Este presupuesto metodológico está en conexión con el problema del siempre origen incierto de la institución, frente al cual las posturas parecen responder a cuatro tipos distintos, que son la abstencionista, la mitificadora, la analítica y la evolucionista.

La postura abstencionista descansa en la renuncia a intentar hallar ese origen al no considerarlo posible, lo que se cnmascara, finalmente, con un desdén aparente hacia el problema. Se parte, pues, de que ninguna teoría es aceptable, y se concluye manifestando que la cuestión no ofrece interés, pues lo importante es la institución en sí, y no de dónde puede haber procedido ${ }^{23}$. La postura mitificadora o romántica entronca las cortes con las asambleas legendarias, considerando que no hay solución de continuidad

$20 \mathrm{Id}$., id., p. 27 En la scgunda op. cit. cn nota 15 , nota $39 \mathrm{cl}$ *muchos॰ parece ser sólo uno, que soy yo. Invoca a Ulmann contra mí, cuando este autor no contempla para nada el casu de Aragón, el cual debe serle bastante desconocido, cosa nada sorprendente ya que no se trata de un especialista de nuestra historia.

2) Gonzill:. AnTON, op. cit., en nota 14, pp. 78 y 80.

22 Id. p. 78. Ni Folz ni Ullman se han referido para nada a Aragón.

${ }^{23}$ Quizá es en lo que desembocó Giménez Soler, según Arregui 
entre unas y otras, por lo que la institución procede así directamente de las reuniones donde se forjaron las libertades aragonesas, en especial los famosos fueros de Sobrarbe ${ }^{24}$. La postura analitica coincide en gran medida con la postura abstencionista, pues, en realidad, sólo le falta extraer la conclusión última de que no es posible llegar a nada ${ }^{25}$.

La postura última o evolucionista es la de los historiadores de las instituciones, generalmente, de procedencia jurídica, pero no siempre $^{26}$. La institución de las cortes aparece, entonces, como el resultado de una evolución, que no puede pretenderse sea lineal e inconfundible, como tampoco puede pretenderse que los que la están impulsando exterioricen sus intenciones, como si actuaran de cara al libro o al aula. Es un hecho el que «cort» o scorte» resulta del romanceamiento de la voz latina «curias, y en la sucesión de uno por otro no puede verse una simple evolución semántica, sino también institucional. La «curia» o «corte» es una asamblea, como también lo es el «concilium» o «concilio», la primera, de orígen romano, y la segunda de origen romano-canónico. Resumiéndose las obligaciones de los súbditos durante la alta edad media en la prestación de eauxilium» y «consilium», y poco propicio el término «concilio» para albergar instituciones laicas y eclesiásticas, el aconsejo» deviene el órgano abierto a través del cual pueden prestar los súbditos uno de sus dos deberes fundamentales, alcanzando la condición honorífica de aconsejeros» los que por su influencia política o técnica eran consultados asiduamente. La ecorte» es una modalidad del aconsejo», a la que caracteriza su intervención en la administración de justicia del rey, conde o señor y en la que destacan expertos en dicha administración de justicia o «jueces de cortes». En la segunda mitad del siglo XII, y coincidiendo con lo que está sucediendo en otros lugares, como en León, la corte se realiza públicamente con la presencia del pueblo del lugar donde se verifica la asamblea, $o$, incluso, la de representantes de algunas ciudades, villas y villeros. Es posible que esto suceda en Aragón hacia $1164^{27}$, y, sobre todo, es singularmente claro en Huesca, en

24 Es el caso de López de Haro, según Arregui.

25 González Antón concluye por no aclarar cuál es para él el régimen de las cortes.

26 Parece ser el caso de Sarasa, que procede de la Facultad de Filosofia y Letras.

27 GONZȦLz ANTON. op. cit. p. 46, siguiendo a del Arco habla de la fecha citada. Cfr. SARASA, op. cit. p. 31. 
$1188^{28}$, fecha que nos impresiona, pues es la misma de la asamblea fundamental de León con Alfonso IX, en la que este reino se adelanta casi en un siglo a la Corona de Aragón, aun cuando posteriormente retroceda, especialmente cuando la dirección política se transmite a Castilla. En cortes de Monzón de 1217 se detecta la presencia de eciudadanos y burgueses», y en 1218 y 1236 la de los calificativos asolemne», «plena» o egeneral» para la corte, lo que está significando el paso de un órgano exclusivo del rey a un órgano conjunto del rey y de los reinos. La intitulación es la de ecortso «corte» en singular, pero no tiene nada de particular que cuando se hable de diversas reuniones pasadas o de la concentración en un punto de los citados instrumentos de gobierno de varios territorios, se hable de «cortes» en plural, y que, posiblemente, la tendencia magnificadora o ampulosa del Renacimiento y, sobre todo, del Barroco, hayan consagrado la costumbre de nombrar en plural una reunión celebrada en singular, lo que, desde el aspecto del lenguaje, es una enormidad, pero a la que nos hemos habituado.

¿Cabe la menor duda de que «corte» y «cortes» es una única denominación? Parece que no, y, por tanto, a una unidad de denominación ha de corresponder una unidad de lo denominado, unidad que no hay que confundir con identidad, en el sentido de que siempre hay que admitir la existencia de una natural evolución. Pues bien, entonces es cuando se introduce una denominación perturbadora, con total falta de respeto a las denominaciones históricas, y que en este caso es la de «asambleas de cortes ${ }^{29}$. Es decir, a las reuniones o asambleas celebradas durante el reinado de Jaime I, por ejemplo, se les denomina «asambleas de corte», en lugar de denominarlas «cortes», con lo que se sugiere que aquéllas son distintas de éstas. ¿En qué documentación se habla de aasambleas de corte»? ¿No se comprende que es un disparate desplazar alegremente un nominativo a un genitivo, e introducir un término cuyo contenido ya estaba asumido por el anterior? Si, precisamente, la «corte» es una asamblea, ¿cómo se va a hablar ahora de una «asamblea de asamblea»? El rey no reúne «asambleas de corte», sino *cortes», y esto lo mismo en el siglo XII, que en el XIII

$28 \mathrm{~J} . M^{2}$ Ramos Loscertales, Textos para el estudio del derec bo aragonés en la Edad Media: 1. Constituciones de las Cortes de Huesca de 1188, AHDE, I, 1924. pp. $398-400$.

29 Lo introduce González Antón, a partir de la p. 46, op. cit. Sarasa no parece incurrir en este error. 
o en el XIV, o en los siglos sucesivos. Podría hablarse de «sesiones» de cortes, lo que sería distinto, pues no atentaría contra la substancia del término. Las cortes no se han celebrado de una sola vez, sino a travếs de distintas reuniones o sesiones, pero eso es distinto. Hay que respetar la denominación histórica, a menos que se ofrezca la debida explicación para evitar cualquier género de confusionismo. Vuelvo a insistir en que, desde el punto de vista de la denominación, son igualmente acortes» las del siglo XII que las del siglo XVII, y a esa unidad de denominación corresponde una unidad de institución, porque son tan acortes s las del siglo XII como las del siglo XVII, lo que no quiere decir que sean «idénticas», es decir, que no hayan experimentado una evolución. ¿Es idéntico el rey del siglo XII al del siglo XVII? Naturalmente que no, pero no negaremos que la institución del rey existe en ambos momentos, y que tan rey es uno como otro institucionalmente, y no llamaremos al rey del siglo XII la afigura del rey» o denominación parecida, que sugiera que el rey no ha existido verdaderamente en el siglo XII.

\section{La conveniencia de la mesura en la utilización de neologismos $y$ anacronismos}

El respeto a las denominaciones históricas no conduce necesariamente al repudio de la utilización de neologismos y anacronis. mos, pues, en todo caso, lo que lleva consigo es a la limitación de esta utilización. Es decir, si existe una denominación histórica, lo que no podemos hacer es introducir un neologismo o un anacronismo para desvirtuar el significado que entraña aquélla. Es, como hemos visto, el caso de sustituir en un determinado momento el término «cortes» por el de «asambleas de corte». Aunque más de una vez me he sentido inclinado a un purismo literario ${ }^{30}$, no soy, sin embargo, adverso al empleo de neologismos y anacronismos, en cuanto aquél puede facilitar la percepción de fenómenos, de otra manera casi incomprensible para el que está separado de éstos por varios siglos. Creo que la cuestión es un problema de mesura,

30 Se ofrece en un buen número de institucionalistas, como Ramos Loscertales, García de Valdeavellano, Font Rius y también Sarasa, salvo en algún caso que se deja arrastrar, como cuando acepta los términos eparlamentario» y epreparlamen. tarios. 
es decir, no debe prodigarse excesivamente; hay que utilizar los adecuados, es decir, los que admiten una justificación y debe hacerse en forma que no induzca al lector a confusión.

En el caso de la fórmula de gobierno del Reino de Aragón, precisamente, en función del papel que desempeñan en él las cortes, no creo que haya inconveniente en hablar de *democracias, sautoritarismo», «estamentalismos, «liberalismo», *parlamentarismo» y denominaciones similares, aunque sabemos que no fueron empleadas por los coetáneos de la institución. Podemos utilizar el término «democracia» si el lector está en condiciones de saber que no nos referimos a la ateniense o a la de Weimar y queremos expresar una fórmula de gobierno en la que el monopolio del poder por su titular cede a una participación de la comunidad ${ }^{31}$. Pretender que el término «democracias se aplique, exclusivamente, a los casos en que sólo la comunidad y toda la comunidad tiene el gobierno efectivo, significa erradicarlo del lenguaje político, pues es sabido que el «demos» en Grecia no comprendía toda la población y que, además, aquél fue burlado por la habilidad de los políticos, como es sabido que la democracia liberal no ha sido considerada tal por el marxismo, o que las «democracias populares» de los países del Este no son consideradas seriamente en ese concepto por los críticos de Occidente.

Si por aliberalismo» entendemos el régimen que concede libertades, y no sólo estamentales, sino individuales, el inaugurado por el Privilegio General es claramente liberal ${ }^{32}$, y podemos emplear este término siempre que el lector no pueda confundirlo con el régimen que, derivado de la Revolución Francesa, antepone a todo lo demás un cuadro de derechos del hombre o libertades individuales ${ }^{33}$.

El término *parlamentarismo* ${ }^{34}$ encierra un peligro, y es el de

31 GONZĀLEZ ANTÓN, op. cit. p. 61, actúa deslealmente cuando no concede importancia a mi inciso sobre la manera en que puede calificar como de edemocracia» a la aragonesa, además de no tener en cuenta, también deslealmente, que lo hago en una mención epígrafe, ni en mis obras de conjunto califico de «democracia* al sistema.

32 Vid. mi artículo «Los derechos individuales en el Privilegio General de Aragón», AHDE, L, Madrid, 1980, Pp. 56-68.

33 Esto me ha llevado a emplear fórmulas estamentales en Derecho bistórico Español, E. Ariel, Barcelona, 1974, p. 218, en lugar de hablar de aliberalismo estamentals, como hacía en Iniciación histórica al Derecho Español, 2a ed., Barce. lona, 1978, parágrafo 517.

34 Lo emplea GONZALIEZ ANTON, op. cit. p. 43 y ss. y le sigue E. SARASA, op. cit. 
denominar «parlamento» a las cortes, es decir, emplearlo en un sentido lato, como cualquier sitio donde se shablas, cuando en Aragón tiene un sentido estricto, con arreglo al cual «cortes es, precisamente, lo que no es *parlamento», y por eso se puede leer en la documentación y en la doctrina la expresión cortes «y» parlamentos, es decir, dos conceptos diferentes. Puede, pues, aplicarse el término «parlamentarismo» si éste lo empleamos en sentido lato y advirtiendo de ello, aunque no deja de ser divertido que lo empleen los que rechazan la aplicación del término edemocracia $^{35}$, pues un aragonés del siglo XIII o XIV abriría la boca de oreja a oreja si oyera que su régimen era calificado de «democrático», pero no creo que la cerrara si oyera que era *parlamentario», y aún la abriría más, hasta desconyuntarla, si oyera que el régimen hasta 1283 había sido pre-parlamentario ${ }^{36}$.

Estos neologismos y anacronismos pueden ayudar a comprender los cambios que se han producido en la fórmula de gobierno aragonesa. Parece que a lo largo del reinado de Jaime I, esa fórmula no difiere mucho de la que existe en otros reinos hispánicos, incluido el de León y Castilla, predominando todavía un régimen autoritario y patrimonialista ${ }^{37}$. Las cortes están experimentando, sin embargo, un notable desarrollo, pues están ampliando su base, aunque sólo la nobleza está proxima a constituir un aestamentos, es decir, un grupo social cerrado con intereses propios, estando ciudades y villas lejos todavía de ello, y aún la Iglesia, en cuanto forma parte de una organización supranacional. Esto no pasa desapercibido a la historiografia antigua, que, desde Zurita a Juan Francisco Andrés de Ustarroz, ha conocido perfectamente cuando se ha incorporado la Iglesia como brazo, y las vicisitudes de ciudades y villas. Cada día más, las cortes se han ido convirtiendo en un instrumento necesario de gobierno, aunque su convocatoria ha permanecido todavía discrecional en el rey. Es en 1283, y en ello es unánime la historiografía moderna, cuando se ha producido un cambio fundamental, y es que el adeber de consejos se ha transformado en un «derecho de reunión ${ }^{38}$. El rey se compromete a convocar periódicamente las cortes y a no legislar sin ellas, declara-

35 Los prefijos «pres, *contras, «antis, etc, implican la renuncia a calificar el período anterior.

36 Es el caso de González Antón, vid. nota 31.

37 Vid. mi Iniciación, cit. en nota 33, parágrafo 517. GONZẢLEZ ANTON, op. cii., p. 51 , subraya la naturaleza de monarquia de derecho divino.

38 Es el lenguaje de E. SARASA, op. cit. p. 30. 
ción que no encontraremos en Castilla, por ejemplo, lo que puede justificar que califiquemos de régimen «democrático», «liberal», aparlamentarios u otra denominación similar, por oposición al de Castilla, aunque no haya que olvidar que en determinados momentos las cortes castellanas hayan estado en condiciones de ejercer mayor presión que las aragonesas, aunque no hayan disfrutado del respaldo jurídico de éstas.

No es cuestión de exponer aquí como se ha producido el cambio, pues la historiografía clásica lo conoció ya, y la contemporánea ha perfeccionado este conocimiento ${ }^{39}$. Como suele suceder, ha sido necesario un movimiento revolucionario, y éste, a su vez, se ha producido cuando ha existido una debilitación del poder. $\mathrm{Si}$ hubiera que elegir un simbolo, podría adoptarse el del Vespro siciliano, en cuanto su gestación y desarrollo es el desencadenante de diversas inquietudes dentro de los territorios de la Corona de Aragón, y, entre ellos, el del éxito de la «jura» o aunión» gestada en Tarazona, y en la que intervienen nobleza y concejos, los componentes de las cortes, aunque fuera de ellas. Al final, es en cortes donde se alegalizas la nueva fórmula de gobierno democrática, liberal, estamental o parlamentaria, a la que caracteriza la consagración jurídica de una concepción compartida del poder entre el rey y el reino, cuyo punto de encuentro lo constituyen las cortes. En adelante el problema lo constituye hallar el punto debido de equilibrio, que la Unión rompe alguna vez en su favor, pero lo que le enajena el apoyo de una amplia mayoría, y que otras veces intenta romper el rey con recursos similares a los de Castilla, pero que tropiezan con una firme resistencia estamental, apoyada en una base ideológica muy fuerte, que, insistiendo en el carácter paccionado de las normas, con arranque en un momento histórico concreto, puede calificarse en el terreno de las categorías como de «pactismo historicista político», en el momento en que un pactismo también historicista, pero de signo juridicista, se está abriendo paso en otros territorios de la Corona, como Cataluña y Valencia $^{40}$.

39 GoNZÄLzZ ANTON, op. cit, en primer lugat, en nota 15.

40 Lo he expuesto en eEl pactismo en los reinos de Aragón y de Valencias en $E I$ pactismo en la Historia de España, Instituto de España, Madrid, 1980, pp. 113 139. Aunque no me vaya a ocupar de ello, tengo que advertir que no considero indiferente el empleo de un neologismo u otro. 


\section{La ineludibilidad de no distorsionar los conceptos jurídicos}

Los conceptos jurídicos, en cuanto fruto de una elaboración mental, no son precisos e inconmovibles, pero tampoco pueden ser distorsionados, ni utilizados caprichosamente. Sólo puede utilizarlos quien los conoce, dándose por descontado que este conocimiento no queda reservado á unos titulados. Es decir, para utilizar los conceptos jurídicos no hace falta ser licenciado o doctor en Derecho, pero hace falta conocerlos. Puede leer un manuscrito antiguo el que no es licenciado o doctor en la sección correspondiente de una Facultad de Filosofía y Letras, pero a condición de que haya aprendido paleografía de la forma que sea. Hay que partir de que el reproche de dogmatismo a los iushistoriadores, sin más, indica un desconocimiento total y completo de aquéllos, pues es en ellos casi centenaria la preocupación y la inquietud por ese dogmatismo, que unos no vacilan en asumir, y otros, sin embargo, rechazan ${ }^{41}$.

En el tema de las cortes aragonesas se produce, precisamente, en los últimos tiempos una distorsión total de los conceptos jurídicos, indudablemente por ignorancia de los mismos, como se verá a continuación.

A través del aludido recurso de introducir subrepticiamente la denominación de «asambleas de cortes» para las que en el siglo XII y en el siglo XIII se denominaron acortes», y no fueron sino eso, es decir, acortes», se llega a decir que las cortes no existen «de derecho» hasta $1283^{42}$. Cualquier estudiante de primer año de Derecho conoce la diferencia que existe entre «derechos y kley», porque, además, es muy sencillo, pero hay que saberlo. ¿Cómo no van a existir *de derechos unas asambleas que convoca el rey con cierta frecuencia, y con el asentimiento de la sociedad, adoptándose en ellas las decisiones políticas de mayor transcendencia? ¿No existen ede derechos las cortes de Huesca de 1247, que fijan todo el ordenamiento judiciario de Aragón, o las de Ejea de 1265 que, en tanto no se demuestre lo contrario, regulan el procedimiento de resolución de las contiendas interestamentales? ${ }^{42}$ bis $\mathrm{El}$

41 No estoy de acuerdo con las manifestaciones de E. SARASA, Op, cit. pp, 22 y ss., concesión a esos lugares comunes que se consagran en una época determinada sin que nadie se moleste en probarlos. Curiosamente, sus conclusiones no se apartan en nada de las que han establecido esos historiadores a los que critica.

42 Afirmación de GONZÁlEZ ANTON, op. cit. en nota 14, p. 46.

42 bis Sobre la importancia de alguna corte anterior, vid. T.N. Bisson, a A Ge- 
disparate es tan mayúsculo que su aceptación llevaria hasta negat la existencia del Reino de Aragón en el siglo XIII, en cuanto la mayoría de sus instituciones no han sido todavía objeto de un fuero o de una ley en esa época. No todos los autores incurren en el crror de confundir ajurídico» $y$ «legal ${ }^{43}$, pero son arrastrados hacia un error de menor entidad, pero que también es un error, como es el de considerar que no existieron "propiamente» hasta ese momento ${ }^{44}$. Eso sería tanto como pensar que las cortes castellanas no han existido nunca epropiamente» porque no disfrutaron de un respaldo legal. Hay que volver a insistir en que las cortes aragonesas han existido desde mucho antes de fines del siglo XIII, en el momento que los historiadores, precisamente, deben rastrear e investigar. El que en 1283 se inaugure uno de los períodos que pueden distinguirse en su evolución es otra cosa, y en ello está de momento todo el mundo de acuerdo, sin olvidar que la institución es la misma, y que lo que ha cambiado es su papel, eso sí, en forma importante.

Otro aspecto en el que se manifiesta la deficiencia en la utilización de los conceptos jurídicos, es en el de la competencia legislativa de las cortes. A la hora de determinar cuándo han nacido las cortes se concede el mayor valor a la declaración formal de las de 1283, pero al señalar la capacidad legislativa de ellas se abandona. Se califica de régimen aparlamentarios al establecido en 1283 , pero luego se pone en duda la capacidad legislativa, o se niega para un período tan rico en actividad legislativa, como es el de Jaime $\mathrm{II}^{45}$, y se consigue proyectar sombras sobre aquella actividad ${ }^{46}$. Lo peor es que se siembra la confusión, es decir, que no se sustituye una teoría antigua bien perfilada, por otra moderna también bien perfilada, sino que todo se deja en el aire. Es preciso, pues, intro-

neral Court of Aragon (Daroca, february 1228), English Historical Review (Oxford), XCII, núm. 362 (1977), pp. 107-124.

43 No se equivoca SARASA, op. cit. p. 34, cuando habla de que se convierte en legal el derecho de los aragoneses a ser consultados

44 SARASA, op . cif, , p. 32, al decir que no existían *propiamentes, parece indiear que no existian ade hechon.

45 GONZȦLZZ ANTON, op. cit. en segundo lugar, en nota 15, p. 625 niega poder legislativo a las cortes, e, incluso, la naturaleza de órgano colegislador. En p. 624 , frente a García de Valdeavellano, dice que, al menos por lo que se refiere al Aragón de esos años, no llegan a tener un poder de legislar.

46 SARASA, op. cit, p. 104, llega a preguntarse si legislaron o no, las Cortes, aunque luego parece decidirse por la afirmativa. 
ducir orden, y para ello utilizar correctamente los conceptos jurídicos.

En primer lugar tienen que delimitarse las diferentes esferas del estudio o de la investigación, es decir, separar el aspecto jurídico del fáctico o sociológico. Desde el punto de vista jurídico-formal no hay duda, y debe ser manifestado así. El rey tiene obligación de legislar junto con las cortes, y esto es válido tanto para Pedro III, como para Jaime II o como para Pedro IV. No es correcto plantearse el problema de si las cortes legislaron o no, por el hecho del alto nivel de incumplimiento de los fuetos salidos de esas cortes, como no lo sería plantearse si el promulgador del código penal actual es un legislador cuando los preceptos de aquél son constantemente infringidos, a no ser que el incumplimiento estuviera tan generalizado que el poder político hubiera sido anulado, lo que no sucedió entonces. Incluso admitir que existe una reivindicación pública del «derecho a no cumplir los fueros» significa que éstos tienen valor legislativo, pues sólo se aspira a incumplir lo que tiene fuerza de obligar. Lamentarse de que haya declaraciones de que «el fuero no valga» es como lamentarse de que el Tribunal Constitucional actual tenga que dictar frecuentes sentencias declasatorias de que hay leyes anticonstitucionales ${ }^{47}$, aparte de no percibir de que esas declaraciones no solamente no atacan la legalidad sino que son precisamente las que la defienden ${ }^{48}$. Creo que hay, pues, un planteamiento totalmente incorrecto del tema, consecuencia de no entender que, aunque paradójico y muy discutible en cuanto a su matización, el Derecho se justifica algunas veces más a través de su incumplimiento que de su cumplimiento, o dicho de otra manera, el Derecho atiende más a los aspectos que pueden ser incumplidos que a los que no necesitan de ninguna intervención para ser cumplidos. Otra cosa distinta es el aspecto sociológico de quién es el que ha ejercido mayor presión a la hora de legislar, pero decir que las cortes con Jaime no legislan por el hecho de que sea éste quien lleve la iniciativa es como negar que en el momento presente legislen las cámaras, por el hecho de que sea el Gobierno o una de las minorías la que tiene más posibilidades de triunfar en la elaboración de las leyes.

Parecido a lo que sucede con la capacidad de legislar es lo que

$47 \mathrm{Vid}$. Gonzälfz ANTON, op. cit. en nota 14, pp. 142-143.

$48 \mathrm{Vid}$. mis observaciones sobre ciertas fórmulas de este tipo en mi Iniciación, parágrafos $180,231,342$, etc., totalmente insospechadas para González Antón. 
sucede con la asunción del conocimiento equivalente de nuestro contencioso-administrativo en materia de agravios, lo que se realiza a través de los «greuges» o agravios derivados de la actuación del rey o de sus oficiales contra algún derecho reconocido por los fueros o leyes, extendido a las contiendas interestamentales o quejas formuladas por los brazos entre sí, o aun los que emprende el rey contra el justicia y sus lugartenientes oficiales. La historiografia moderna tiende a teducir la importancia de esta función por la prisa al efectuarla, o por la escasa importancia de los agravios planteados ${ }^{49}$, y tambiến por la poca expresividad de los textos conservados en los registros ${ }^{50}$. Esperemos los resultados de futuras investigaciones, pues indudablemente es de gran interés conocer lo que podríamos denominas saspecto cuantitativos, aunque hay que advertir sobre el error que supondría valorar una institución, exclusivamente por lo que ha hecho, pues es fundamental también lo que podía haber hecho. Al valorar, por ejemplo, en el futuro el papel de nuestras Audiencias actuales, indudablemente, deberá conocerse el número de asuntos despachados y la calidad de estos asuntos. Su incidencia en la sociedad no será la misma si ha despachado doscientos casos anuales que si ha solucionado dos mil, pero la circunstancia de que estos casos hayan sido de escasa cuantía económica o que las penas discutidas hayan sido de pequeña entidad no rebajará la importancia de una institución, si la competencia de ésta podía haberse ejercitado en asuntos de mayor cuantía o de importancia penal más elevada. Colocados en un plano sociológico, no sólo habrá que ponderar los agravios resueltos por las cortes, sino los que éstas evitaron que se produjeran, de la misma manera que la eficacia de un guardia no se manifiesta exclusivamente por el número de delincuentes aprehendidos sino también por los ahuyentados.

Parece que existen menos discrepancias en cuanto a las cortes como instrumento de financiación de las empresas reales por el reino, pues se reconoce unánimemente que ha sido función de aquéllas la votación de la ayuda económica que han necesitado los reyes para sus empresas, fundamentalmente bélicas, y que, incluso, en ello ha residido la verdadera fuerza de presión. Son loables los esfuerzos actuales para detectar su evolución a través del estu-

49 GONZALEZ ANTON, op. cit., p. 133 y ss.

so SARASA, op. cit., p. 94 y ss. 
dio concreto de las actuaciones ${ }^{51}$, y en el momento actual disponemos, afortunadamente, del proceso de gestación de un aservicio», como es el de las cortes de Tamarite de $1375^{52}$. Sin embargo, se ha avanzado muy poco en el terreno conceptual desde los ya lejanos días de Ignacio de Asso, que en su día corrigió a Blancas a la hora de señalar la fecha del primero de los servicios ${ }^{53}$. Es preciso detectar el fenómeno del recurso del rey a los tributos extraordinarios en el siglo XIV, precisamente ante la insuficiencia de los recursos ordinarios, parcialmente favorecida por la concepción paccionada del poder, que prohibía la imposición de nuevos tributos sin el consentimiento del reino. Esos recursos son conocidos como «subsidios», aservicios», adonativos» o «donos» y «profiertas», denominaciones que no siempre se emplean con su verdadero sentido, pero que encierran conceptos distintos. El término ssubsidio» es el más general, pudiendo ser sinónimo de eservicio extraordinario real». El aservicios es el subsidio para el mantenimiento de tropas, el cual puede realizarse por la vía del préstamo, que es lo que se denomina «profierta», o por la vía de donación, que es lo que recibe el nombre de «donativo» o «dono», pudiéndose empezar por la primera forma, en tanto se discute sobre la posibilidad de llegar a la segunda, naturalmente más deseada por el rey, y menos por el reino. El «servicio» es así género, del que «profierta» $y$ «donativos son especies, normalmente, pero cabe también que el último no tenga por objeto el mantenimiento de tropas, en cuyo caso no es un eservicios ${ }^{54}$. Es decir, como ocurre generalmente en el terreno de las instituciones, no puede pretenderse la ausencia total de deficiencias en el empleo de la terminología, sin que por ello ésta sea anulada.

Hay que insistir en la necesidad de captar la base ideológica de los fenómenos, y la interdependencia existente entre éstos. La escasez de recursos económicos del monarca al amparo de una ideología patrimonialista le ha forzado a buscar la aportación del reino, que sólo podía conseguirse a través del instrumento de las cortes, las cuales, a su vez, han visto así inctementada su potencia. Su

51 Vid. Gonzallez Anton, op. cit., pp. 55 y ss. y p. 136 y ss. o SARASA, op. cit. . PP. 98 y ss. El primero suministra información interesante.

52 Ha sido facilitado por el trabajo de M* L. Ledesma Ramos, cit. en nota 13.

53 Me refiero a su espléndida *Historia de la Economía Política de Aragón», Zaragoza, 1798, reeditada en 1947.

54 Todo ésto en eLa base ideológica del sistema impositivo aragonés histórico», mi aportación al homenaje tributado a D. Luis García de Valdeavellano. 
origen no ha estado en la función de financiamiento, sino en la prestación de consejo, pero su capacidad como instrumento de financiación es lo que les ha comunicado su verdadera fuerza de presión, y con ello su importancia política, de la que no han carecido las cortes de otros reinos, como las castellanas, aunque hayan tenido menor importancia en la creación jurídica.

La recreación de la imagen antigua por la visión moderna, como objetivo de la investigación actual

Hay que superar el viejo problema de si las instituciones del pasado hay que verlas con los ojos de entonces o con los actuales. No podemos verlas con los ojos del pasado, porque dejaron de mirar, sino con los ojos nuestros, los únicos que ven y que tienen vida. Sin embargo, lo que sí podemos y debemos hacer es no extender nuestra mirada sobre el pasado directamente, sino a través de las imágenes que una vez estuvieron en la retina de los antiguos, y que ellos cifraron en el código de su escritura. Esto es importante para problemas como el de la unidad de la institución, la representatividad o la periodificación.

Con motivo de otto presupuesto metodológico, el de la conveniencia de respetar las denominaciones históricas, se ha defendido aquí la unidad institucional de las cortes, desde la alta edad media hasta su desaparición a principios del siglo XVIII, sin perjuicio de que hayan sufrido una notable evolución. Esto se refuerza con el de la imagen antigua, en cuanto que la historiografía clásica no ha dudado nunca sobre ello. Hasta el propio Zurita, y no digamos los demás, llama «cortes» a las del siglo XII, por ejemplo, y, naturalmente, porque las considera cortes, iguales a las de su tiempo. Si ningún autor medieval o del Renacimiento y del Barroco han puesto en duda la citada unidad institucional, ¿por qué lo vamos a hacer nosotros? ¿No es esto’ser, como se dice vulgarmente, amás papista que el Papas? Podremos clasificarlas, tipificarlas, etiquetarlas, valorarlas, compararlas y realizar cuantas operaciones queramos, a condición de no alterar la imagen antigua, que es la de unidad de denominación correspondiente a unidad institucional. Subsiste la unidad de denominación, pero se trunca la unidad de institución cuando pasamos a las cortes constitucionales, pero es que entonces la imagen antigua varía, es decir, los coetáneos de su introducción nos testimonian que se trata de otra cosa, sin perjui- 
cio de enraizarlas, es decir, de buscar antecedentes y justificarlas en un espíritu nacional. Al decir que las cortes constitucionales son otra cosa que las cortes medievales o estamentales estamos respetando la imagen 0 , mejor dicho, las dos imágenes antiguas, en tanto que cuando decimos que las cortes del siglo XIV son otra cosa que las cortes o que las «asambleas de corte» de los siglos XII o XIII, estamos destruyendo la imagen antigua injustificadamente.

Creo que la unidad institucional de las cortes es lo que ha impedido a la historiografía clásica incurrir en la deformación de la moderna cuando le cuesta digerir el paso de unas cortes no nacionalistas a unas cortes nacionalistas. La «cortes es un instrumento del rey, que, gradualmente, se va convirtiendo en un instrumento del rey ay de los reinosx y no del rey y de cada reino. El rey puede convocar indistintamente a aragoneses y catalanes, aunque no lo hará en forma arbitraria, sino atendiendo a la nacionalidad de los asuntos a tratar 0 , incluso, a las posibilidades físicas de asistencia. Por ello, si convoca la corte en Zaragoza o en Huesca convocará casi en exclusividad a los aragoneses, o a los catalanes cuando convoca en Barcelona o en Tortosa. Es más, la celebración de la corte en lugares intermedios, como Monzón o Lérida, lleva consigo la posible participación común de aragoneses y de catalanes. Durante el reinado de Jaime I se camina hacia lo que hoy denominariamos unas cortes «nacionales», esto es, hacia unas cortes aragonesas y otras catalanas, como también hacia unas cortes valencianas, y este fenómeno se halla en conexión con la fijación de límites territoriales, a la que Jaime I se ve abocado al divorciarse de su primera mujer y tener hijos con la segunda, todo ello acompañado de su intención de dividir los reinos. Es un hecho incontestable que a los efectos de delimitar la paz y tregua en Cataluña es en cortes donde se establecen las fronteras de este país, y que esas cortes a fines del siglo XIII se han *nacionalizado», sin que la transición inquiete a la historiografía clásica, pese a que ésta se desenvuelve en un clima de nacionalismo frente al rey, tras varios siglos de nacionalismo anticatalán. Parte de la historiografía moderna niega que el desarrollo de las cortes haya contribuido a la delimitación de Cataluña y Aragón, y parece ique se insinúa el fenómeno contrario de ser la delimitación la que da lugar al desarrollo de las cortes $^{55}$. Parece exagerado que se niegue el pan y la sal a las cortes hasta el punto

5s Lo dice GONZALEZZ ANTON, op. cit. p. S2, y asi hay que interpretar una cita obscura y que no tiene nada que ver con la realidad española. 
de que ni siquiera shayan contribuidos a la formación de unas conciencias nacionales, pero tampoco hay inconveniente en reconocer que habrán sido las conciencias nacionales las que habrán dado lugar a las cortes nacionales. Lo que sucede es que las conciencias nacionales necesitan vehículos de canalización, y uno de ellos hay que suponer ha sido la reiterada coincidencia en asambleas por parte de los que por comunidad de lengua, territorio, necesidades económicas y aspiraciones se han sentido más próximos entre sí, que en relación a los demás.

El presupuesto del que tratamos hay que tenerlo en cuenta en el problema de la «representatividad» de las cortes, muy importante, pues en este mismo ciclo las cortes son estudiadas como formando parte de las instituciones arepresentativas», y es muy probable que hayan sido programadas como la institución de mayor representatividad. Es claro que la representarividad es consubstancial a las cortes, o, dicho de otra manera, el mayor o menor valor de las cortes reside en su mayor o menor capacidad de representatividad. La historiografía moderna tiende a resaltar la escasa representatividad ${ }^{56}$, y tiene completa razón desde el punto de vista de una óptica moderna, en el que se aspira a una democracia perfecta, y se pasa de sistemas censitarios al sufragio universal, o se discute entre distintos tipos de elección, a más de preocupar un buen censo de población. Ahora bien, es preciso también mirar a través de la imagen proporcionada por la historiografia clásica, a la que el problema no parece interesar, y ello aunque algunas de las figuras que la integran desarrollan en su tiempo un papel que hoy calificaríamos de eprogresistas. Hay que distinguir, pues, entre la representatividad según nuestra concepción y la representatividad según la concepción de los coetáneos. En la edad media no se pretendió nunca que la representatividad fuera total, entre otras cosas porque no existía la técnica indispensable para conseguirla, y me refiero en especial al brazo de las universidades. Interesa el problema cuando se refiere a la nobleza, porque ésta, por regla general, no necesita de representación, o se representa a sí misma, y, por tanto, los problemas que ofrece son solubles, como qué es lo que sucede si el noble es mujer, o si, heredado en Aragón, reside en otro territorio. Tampoco la Iglesia ofrece problemas, pues

56 P. c. GONZÃLEZ ANTON, op, cit. p. 120 y ss., que la ataca y facilita información interesante, o SARASA, op. cit. p. 83 y ss. que se mueve en un terreno más formalista, y destaca las dificultades. 
ella misma, bien organizada, puede dar los problemas resueltos. Los problemas se ofrecen con ciudades, villas y villeros, cada una de las cuales se preocupa de estar representada en cortes, y no siempre a través del brazo de las universidades, sino, a veces, en el de la nobleza, especialmente en el de la baja, es decir, el de caballeros $\mathrm{e}$ infanzones. Todo esto se resume, pues, en que al tratar de la representatividad, como en cualquier otro problema, hay que distinguir diversos planos. La institución debe haber satisfecho las aspiraciones de representatividad, aunque pueda haber localidades que se hayan sentido preteridas, y en este sentido las cortes medievales son tan representativas como lo son las nuestras para nosotros, que no lo serán, posiblemente, en el futuro, cuando se arbitren medios para la representatividad de los menores de edad, de los dementes o de los anormales. Recuérdese el caso actual de Suiza, modelo democrático en el que todavía se discute el voto femenino. Es decir, la representatividad no está en función de toda la población, sino de la que se considera comunidad activa en cada momento, y ésta era muy restringida en la edad media, y sin que ello signifique una defensa del modelo medieval, pues, precisamente el progreso de la humanidad reside en ampliar la comunidad activa hasta identificarla con la población total.

Otro fenómeno en el que hay que tener en cuenta el presupuesto metodológico de que aquí se trata es el de la periodicidad de las cortes. La historiografía actual pone mucho énfasis en el incumplimiento de la anualidad o bianualidad de las cortes ${ }^{57}$, y ello es conveniente, pues es la constatación de un hecho de indudable trascendencia en cuanto al verdadero papel ejercido por la institucion. Lo peligroso es darle categoría de descubrimiento ${ }^{58}$, o atribuirle más significado del que tuvo, a pesar de que tuvo mucho. pesar de que la tuvo y mucha.

La imposición de una periodificación de altísima frecuencia que la Unión impone a Pedro III es paralela a la que los otros territorios de la Corona de Aragón, como Cataluña y Valencia, están imponiendo, e implica un verdadero régimen asambleario, en el

57 P. E SARASA, P. 67 y 55.

58 GONZÁLEZ ANTON, en op. cit. en segundo lugar de la nota 15 llega poco menos que a imputarme un desconocimiento del grado en que se llevó a efecto la periodificación, sin darse cuenta de que en *Derecho histórico español me me estoy refiriendo al mundo de las normas, pues no hace falta saber mucha historia para conocer que las cortes no se reunieron anual o bianualmente. 
que, con arreglo a nuestro lenguaje político de hoy, el poder ejecutivo queda a merced del poder legislativo. Este régimen asambleario sólo puede ser el efecto de una euforia política desmedida, que es la que se manifiesta también en los intentos de imponer un consejo al rey, o de consagrar la posibilidad de deponerle. No creo que ni los más exaltados pensaran seriamente mucho tiempo en la factibilidad de la solución, aunque sólo fuera por las dificultades de su financiación. Debe tenerse en cuenta que reunir los representantes del reino anualmente implica lo que hoy denominamos una «infraestructura», difícil de poseer en aquellos tiempos. Que así lo entendieron, lo demuestra el que pronto sustituyeron la anualidad por la bianualidad, y aún por la trienalidad en otros territorios. Creo que la intención del reino no ha sido en ningún momento, salvo quizá en los ya aludidos de una desmedida euforia política, el de imponer asambleas anuales o bianuales, sino el de poder reivindicarlas con esa periodicidad cuando fuere oportuno, lo que, por otra parte, parece que no han hecho después en ningún momento. Realmente, todo órgano colegiado tiene a estipular una periodicidad en sus reuniones, condicionada a que alguno de los componentes lo desee, no considerándose incumplimiento del deber cuando la ausencia de su práctica tiene lugar con el consentimiento general, explícito o tácito.

Obsérvese tambiến que el reino consideraba ese derecho como ya existente, pues había sido edespojados de él, y es indudable que, anteriormente, las cortes no se habían reunido anualmente. És decir, lo que consideraban es que poseían el derecho a que la corte se reuniera anualmente si ellos lo deseaban. Desde luego, la historiografía clásica, aunque situada a distancia y sin conocimiento directo, no manifiesta sorpresa e, incluso, Bardaxí, uno de los más destacados foristas, en alguna ocasión da por descontado que ese deber se refiere al caso de ser posible ${ }^{59}$. Es una declaración formal, que sólo el no jurista puede interpretar al pie de la letra.

\section{Conclusiones}

La renovación de los estudios institucionales sobre las cortes medievales aragonesas no debe hacerse sobre la base de destruir sistemáticamente los logros consagrados por la historiografía clásica y

59 He aportado esta cita de Bardaxi en uno de los trabajos que aparecerán en breve. 
depurados por los historiadores de las instituciones de nuestro siglo. La originalidad a todo trance puede perjudicar el veraz conocimiento del pasado. Las cortes aragonesas ofrecen unidad institucional a lo largo de la edad media y de la moderna, desde sus orígenes en la ecorte» del rey hasta su desaparición en los albores del siglo XVIII. La institución se desenvuelve en todo momento, y de manera indudable, dentro del más estricto marco del Derecho, y adquiere legalmente la competencia legislativa, que desarrolla conjuntamente con el rey, siendo reconocida su periodicidad. Las cortes aragonesas son de naturaleza representativa, y, en general, han debido satisfacer las aspiraciones de representatividad de la época, asumiendo, además, la solución de las contiendas interestamentales y el conocimiento de los agravios inferidos a los particulares por los oficiales del rey, y desarrollando su principal fuerza de presión política a través de su insoslayable condición de instrumento de financiación de las empresas reales. Naturalmente, a lo largo de siete u ocho siglos de vida de la institución, todos esos rasgos son la resultante de pasos hacia adelante y de retrocesos, de titubeos y de vacilaciones, o de cumplimientos e incumplimientos. Los historiadores pueden investigar todas las trayectorias seguidas, con lo que la institución adquirirá sus verdaderos perfiles. Ahora bien, los rasgos aludidos de la institución no deben ser puestos en duda y destruidos, a menos que se pueda argumentar sólidamente contra ello observando los presupuestos metodológicos a los que se ha hecho referencia, $y$ a aquellos otros que sirvan para garantizar la fidelidad del razonamiento. Todo lo que no sea argumentar de esa manera sólo puede sembrar la confusión, sin conducir, desde luego, a una mejora de nuestros conocimientos actuales. 